\title{
Effect of irradiance and nitrate levels on the relationship between gross photosynthesis and electron transport rate in the seagrass Cymodocea nodosa
}

\section{Efecto de la irradiancia y la concentración de nitrógeno en la relación entre la fotosíntesis bruta y la tasa de transporte electrónico en la fanerógama marina Cymodocea nodosa}

\author{
Alejandro Cabello-Pasini ${ }^{*}$, Roberto T Abdala-Díaz², Víctor Macías-Carranza ${ }^{1}$, Félix L Figueroa ${ }^{2}$ \\ ${ }^{1}$ Instituto de Investigaciones Oceanológicas, Universidad Autónoma de Baja California, Apartado postal 453, \\ Ensenada, Baja California 22800, México \\ 2 Departamento de Ecología y Geología, Facultad de Ciencias, Universidad de Málaga, E-29071, Málaga, Spain \\ * Corresponding author. E-mail: acabello@uabc.edu.mx
}

\begin{abstract}
The relationship between gross photosynthesis (GPS) and electron transport rate (ETR) in marine algae has been shown to vary as a function of irradiance; however, little is known about the effect of nutrients on the this relationship in seagrasses. The objective of this study was to evaluate the effect of nitrate concentration on the GPS (measured as $\mathrm{O}_{2}$ evolution) vs ETR (estimated by fluorescence quenching analysis) relationship of the seagrass Cymodocea nodosa from the Spanish Mediterranean Sea. Carbon levels in the tissue increased 6.5\% when nitrate in the culture medium augmented from 0 to $100 \mu \mathrm{M}$. Nitrogen in the tissue, however, increased more than $60 \%$ when nitrate concentration in the medium reached $100 \mu \mathrm{M}$. Chlorophyll $a+b$ levels increased approximately $30 \%$, while absorptance augmented $15 \%$ when nitrate increased from 0 to $100 \mu \mathrm{M}$. In general, maximum oxygenic photosynthesis and maximum ETR values increased when nitrate in the medium increased. The relationship between GPS and ETR did not show a linear response at low nitrate levels and high irradiances. In contrast, a linear relationship was observed at nitrate levels above $50 \mu \mathrm{M}$, even at high irradiances. The results from this study suggest that the lack of correlation between ETR and GPS is the result of low nitrogen levels in the tissue of marine macrophytes. They also suggest that seasonal fluctuations in nitrate levels or nitrogen pulses, such as those observed during upwelling events, may affect the relationship between GPS and ETR in C. nodosa or other marine macrophytes.
\end{abstract}

Key words: Cymodocea nodosa, electron transport rate, photosynthesis, nitrate, seagrass.

RESUMEN. La relación entre la fotosíntesis bruta (FB) y la tasa de transporte electrónico (TTE) en algas marinas varía en función de la irradiancia; sin embargo, poco se sabe sobre el efecto de la concentración de nutrientes sobre la relación entre FB y TTE en fanerógamas marinas. El objetivo de este estudio fue evaluar el efecto de la concentración de nitrato sobre la relación FB (determinada como evolución de $\mathrm{O}_{2}$ ) vs TTE (estimada mediante análisis de fluorescencia) en la fanerógama marina Cymodocea nodosa de la costa del Mediterráneo español. Los niveles de carbono en el tejido incrementaron 6.5\% cuando el nitrato del medio aumentó de 0 a $100 \mu \mathrm{M}$. En contraste, los niveles de nitrógeno en el tejido aumentaron más de $60 \%$ cuando los niveles de nitrato alcanzaron $100 \mu \mathrm{M}$. Los niveles de clorofila $a+b$ incrementaron aproximadamente $30 \%$, mientras que la absorptancia aumentó $15 \%$ cuando el nitrato aumentó de 0 a $100 \mu \mathrm{M}$. En general, los valores de fotosíntesis máxima $\left(\mathrm{O}_{2}\right)$ y los valores de TTE máxima incrementaron cuando los niveles de nitrato aumentaron en el medio. La relación entre FB y TTE no mostró una respuesta lineal a bajas concentraciones de nitrato en el medio y a altas irradiancias. En contraste, una relación lineal fue observada cuando los niveles de nitrato fueron mayores a $50 \mu \mathrm{M}$, aun a altas irradiancias. Los resultados de este estudio sugieren que la falta de correlación entre FB y TTE es el resultado de los bajos niveles de nitrógeno en el tejido de macrófitos marinos. Los resultados sugieren también que fluctuaciones estacionales de los niveles de nitrato o pulsos de nitrógeno, como los observados durante eventos de surgencia, podrían afectar la relación entre FB y TTE en C. nodosa y otras macrófitos marinos.

Palabras clave: Cymodocea nodosa, tasa de transporte electrónico, fotosíntesis, nitrato, fanerógama marina.

\section{INTRODUCTION}

The ecological role of seagrasses in estuaries and coastal systems has been well established. In the Mediterranean Sea, for example, Posidonia oceanica and Cymodocea nodosa are the main submerged aquatic vegetation components of sandy and rocky coastal areas (Cancemi et al. 2002, Olesen et al. 2002). Similarly, Zostera marina is the most abundant

\section{INTRODUCCIÓN}

El papel ecológico de las fanerógamas marinas en estuarios y sistemas costeros ha sido bien establecido. Por ejemplo, en el mar Mediterráneo, Posidonia oceanica y Cymodocea nodosa son la principal vegetación acuática sumergida de zonas costeras arenosas y rocosas (Cancemi et al. 2002, Olesen et al. 2002), mientras que Zostera marina 
submerged aquatic plant in the coastal lagoons of Baja California, Mexico, accounting for the bulk of the plant biomass in these systems (Cabello-Pasini et al. 2002, 2003). These seagrass meadows serve as habitat and forage for a vast number of marine organisms (Quiroz-Vázquez et al. 2005, Schrandt et al. 2015). Productivity and biomass of these seagrasses vary seasonally as a result of changes in environmental conditions, such as nitrogen concentration in the water. Nitrogen and carbon concentrations in the tissue of marine macrophytes also fluctuate as a result of nitrogen availability, irradiance, and temperature (Corzo and Niell 1991, Cabello-Pasini et al. 2004). In seaweeds, tissue absorptance generally covaries with chlorophyll and nitrogen content, and consequently varies seasonally as a result of irradiance or nitrogen concentration in the medium (OchoaIzaguirre and Soto-Jiménez 2013). The effect of seawater nitrate concentration on the internal carbon and nitrogen levels as well as bio-optical properties in seagrass shoots, however, are less understood.

Generally, the evaluation of plant photosynthetic rates has been conducted using oxygen evolution or carbon incorporation methods. Fluorometric methods, however, have become common procedures for the study of photosynthesis in marine angiosperms in the last two decades (Ralph and Burchett 1998, Beer and Bjork 2000, Figueroa et al. 2002, Beer and Axelsson 2004). Pulse amplitude modulated (PAM) fluorometry of in vivo chlorophyll fluorescence associated with photosystem II (PSII) evaluates primary reactions and quenching mechanisms under natural or artificial light conditions (Genty et al. 1989). Electron transport rate (ETR) has been shown to be positively correlated to oxygen evolution and $\mathrm{CO}_{2}$ fixation, especially in $\mathrm{C}_{4}$ plants, as long as environmental stresses do not impose restrictions on photosynthetic $\mathrm{CO}_{2}$ metabolism (Genty et al. 1989, Edwards and Baker 1993). In some seaweeds and seagrasses, however, oxygen evolution and ETR have been shown to be ambiguous, especially at high irradiances (Beer and Axelsson 2004).

Photosynthetic characteristics of seagrasses are dependent on irradiance, temperature, tissue type, and light history of the sample. While the effects of temperature and irradiance on the photosynthetic characteristics of seagrasses have been well established (Beer and Axelsson 2004), less is known regarding the effect of nutrient concentration on ETR in these aquatic macrophytes. Similar to marine macroalgae, it has been observed that optimum quantum yield covaries with $\mathrm{Si}$ and $\mathrm{P}$ concentrations in phytoplankton (Kolber et al. 1990, Babin et al. 1996, Young and Beardall 2003). Furthermore, the relationship between ETR and gross photosynthesis (GPS) in the Chlorophyta Ulva rigida and in the Rhodophyta Porphyra leucosticta has been shown to be dependent on the nitrogen content in the medium (Figueroa et al. 2003, Cabello-Pasini and Figueroa 2005). While seagrass populations are often exposed to large fluctuations in nitrogen concentration (i.e., upwelling events, Zaitsev et al. 2014), the effect of nitrogen concentration on the ETR-GPS es la planta acuática sumergida más abundante en las lagunas costeras de Baja California, Mexico, donde representa la mayor parte de la biomasa vegetal (Cabello-Pasini et al. 2002, 2003). Las praderas marinas ofrecen hábitat y alimento a un gran número de organismos marinos (Quiroz-Vázquez et al. 2005, Schrandt et al. 2015). La productividad y biomasa de las fanerógamas marinas varían estacionalmente en respuesta a los cambios de las condiciones ambientales, como la concentración de nitrógeno en el agua. Las concentraciones de nitrógeno y carbono en el tejido de macrófitos marinos también fluctúan como resultado de la disponibilidad de nitrógeno, la irradiación y la temperatura (Corzo y Niell 1991, Cabello-Pasini et al. 2004). En las fanerógamas marinas, la absorptancia del tejido generalmente varía en función del contenido de clorofila y nitrógeno y, por ende, varía estacionalmente como resultado de la irradiación o la concentración de nitrógeno en el medio (Ochoa-Izaguirre y Soto-Jiménez 2013). Por otro lado, se tiene poco conocimiento del efecto de la concentración de nitrato en agua de mar sobre los niveles internos de carbono y nitrógeno, así como de las propiedades bioópticas de los haces de fanerógamas marinas.

En general, la evaluación de las tasas fotosintéticas de las plantas se ha realizado con métodos para determinar la evolución del oxígeno o la incorporación del carbono. En las últimas dos décadas, sin embargo, los métodos fluorimétricos se han convertido en procedimientos comunes para el estudio de la fotosíntesis en angiospermas marinas (Ralph y Burchett 1998, Beer y Bjork 2000, Figueroa et al. 2002, Beer y Axelsson 2004). La fluorimetría de pulsos de amplitud moderada (PAM) de la fluorescencia de la clorofila in vivo asociada con el fotosistema II (PSII) evalúa las reacciones primarias y los mecanismos de desactivación fluorescente (quenching) en condiciones de luz natural o artificial (Genty et al. 1989). La tasa de transporte electrónico (TTE) se correlaciona positivamente con la evolución del oxígeno y la fijación de $\mathrm{CO}_{2}$, especialmente en las plantas $\mathrm{C}_{4}$, siempre y cuando los estresores ambientales no impongan restricciones al metabolismo fotosintético del $\mathrm{CO}_{2}$ (Genty et al. 1989, Edwards y Baker 1993); sin embargo, se ha mostrado que en algunas algas y fanerógamas marinas, la evolución del oxígeno y la TTE son ambiguos, especialmente a altas irradiancias (Beer y Axelsson 2004).

Las características fotosintéticas de las fanerógamas marinas dependen de la irradiación, la temperatura, el tipo de tejido y el historial de luz de la muestra. Los efectos de la irradiación y temperatura en las características fotosintéticas de las fanerógamas marinas han sido bien establecidos (Beer y Axelsson 2004), pero hay poca información sobre los efectos de la concentración de nutrientes en la TTE de estas plantas acuáticas. Al igual que las macroalgas marinas, se ha observado que el rendimiento cuántico óptimo varía en función de las concentraciones de Si y P en el fitoplancton (Kolber et al. 1990, Babin et al. 1996, Young y Beardall 2003). Además, se ha mostrado que la relación entre la TTE 
relationship is unknown. Consequently, the objective of this study was to evaluate the effect of nitrate concentration on GPS and ETR of the seagrass C. nodosa under laboratory conditions. Since nitrogen metabolism relies on carbon precursors, adenosine triphosphate (ATP), and reductants formed during photosynthesis, the examination of the relationship between different elemental (nitrogen and carbon contents), bio-optical (absorptance), and physiological (photosynthesis and respiration rates) parameters will give new insights into the interactions between nitrogen and carbon metabolism in C. nodosa in particular and seagrasses in general.

\section{MATERIALS AND METHODS}

\section{Plant material}

In March 2005, the seagrass Cymodocea nodosa (Ucria) Ascherson was collected from the intertidal zone of Fuengirola, Spain $\left(36^{\circ} 32^{\prime} \mathrm{N}, 4^{\circ} 37^{\prime} \mathrm{E}\right)$, and transported in ice coolers to the laboratory. Shoots of approximately $10 \mathrm{~cm}$ in length (approximately $2 \mathrm{~g}$ total fresh weight [FW]) were incubated from two to three weeks in six acrylic containers (2 L, 15 samples per container) with seawater containing $10 \mu \mathrm{M} \mathrm{PO}_{4}{ }^{3-}$ and $0,2,5,25,50$, and $100 \mu \mathrm{M} \mathrm{NO}_{3}^{-}$. Seawater for medium preparation contained less than $1 \mu \mathrm{M} \mathrm{NO}_{3}{ }^{-}$and $\mathrm{NH}_{4}^{+}$. Nutrients were added and seawater was changed every day. Samples were supplied with an irradiance of $100 \mu \mathrm{mol}$ photon $\mathrm{m}^{-2} \mathrm{~s}^{-1}$ using daylight fluorescent lamps (Osram FL $18 \mathrm{~W}$ ) and were kept on a 14:8 h (light:dark) photoperiod. Shoots were anchored to the bottom of the containers by tying their rhizomes to a weighted plastic mesh. The culture medium was maintained at $15^{\circ} \mathrm{C}$ and kept in constant movement by bubbling air into each container.

\section{Chlorophyll and CHN determination}

Chlorophylls $a$ and $b$ were extracted in N,N-dimethylformamide (DMF) according to Inskeep and Bloom (1985). Tissue samples $\left(2.5 \mathrm{~cm}^{2}, n=6\right)$ were incubated in $3 \mathrm{~mL}$ of DMF for $24 \mathrm{~h}$ at $4{ }^{\circ} \mathrm{C}$ in darkness. Absorbance was determined using a spectrophotometer and chlorophyll concentration was estimated using the equations proposed by Porra et al. (1989).

After the incubation period, samples were dried at $60^{\circ} \mathrm{C}$ until constant weight was obtained. Total intracellular carbon and nitrogen contents $(\mathrm{g} / \mathrm{g})$ were determined $(n=6)$ using a PerkinElmer elemental analyzer (model $2400 \mathrm{CHN}$ ).

\section{Oxygen evolution and chlorophyll fluorescence}

Photosynthetic rates in C. nodosa shoots were determined using polarographically-measured rates of steady-state $\mathrm{O}_{2}$ evolution (Rank Brothers, UK). Tissue $(n=6)$ of approximately $0.2 \mathrm{~g}$ FW was incubated in seawater $(2.2 \mathrm{mM}$ y la fotosíntesis bruta (FB) en la clorofita Ulva rigida y la rodofita Porphyra leucosticta depende del contenido de nitrógeno en el medio (Figueroa et al. 2003, Cabello-Pasini y Figueroa 2005). A pesar de que las poblaciones de fanerógamas marinas frecuentemente están expuestas a grandes fluctuaciones en la concentración de nitrógeno (i.e., eventos de surgencia, Zaitsev et al. 2014), se desconoce el efecto de la concentración de nitrógeno en la relación FB-TTE. Por lo tanto, el objetivo de este estudio fue evaluar el efecto de la concentración de nitrato sobre la FB y TTE de la fanerógama marina C. nodosa en condiciones de laboratorio. Ya que el metabolismo del nitrógeno es dependiente de los precursores del carbono, el adenosín trifosfato (ATP) y los reductores que se forman durante la fotosíntesis, el análisis de la relación entre diferentes parámetros elementales (contenido de nitrógeno y carbono), bioópticos (absorptancia) y fisiológicos (tasas de fotosíntesis y respiración) proporcionará mayor conocimiento de las interacciones entre el metabolismo del nitrógeno y carbono en $C$. nodosa en particular y en las fanerógamas marinas en general.

\section{MATERIALES Y MÉTODOS}

\section{Material vegetal}

En marzo de 2005, la fanerógama marina Cymodocea nodosa (Ucria) Ascherson se recolectó de la zona intermareal de Fuengirola, España ( $\left.36^{\circ} 32^{\prime} \mathrm{N}, 4^{\circ} 37^{\prime} \mathrm{E}\right)$, y se transportó en hieleras al laboratorio. Se incubaron haces de aproximadamente $10 \mathrm{~cm}$ de largo ( 2 $\mathrm{g}$ de peso fresco [PF] total) durante dos a tres semanas en seis contenedores de acrílico de $2 \mathrm{~L}$ (15 muestras por contenedor) con agua de mar que contenía $10 \mu \mathrm{M}$ de $\mathrm{PO}_{4}{ }^{3-}$ y $0,2,5,25,50$ y $100 \mu \mathrm{M}$ de $\mathrm{NO}_{3}{ }^{-}$. El agua de mar para la preparación del medio contenía $<1 \mu \mathrm{M}$ de $\mathrm{NO}_{3}{ }^{-}$y $\mathrm{NH}_{4}{ }^{+}$. Se adicionaron nutrientes y el agua de mar se cambió diariamente. Las muestras fueron expuestas a una irradiancia de $100 \mu \mathrm{mol}$ fotón $\mathrm{m}^{-2} \mathrm{~s}^{-1}$ con lámparas fluorescentes de luz blanca (Osram FL 18W) y se mantuvieron bajo un fotoperiodo de 14:8 h (luz:oscuridad). Los rizomas se ataron a una malla de plástico en el fondo de los contenedores para anclar las plantas. El medio de cultivo se mantuvo a $15^{\circ} \mathrm{C}$ y en constante movimiento mediante la introducción de burbujas de aire en cada contenedor.

\section{Determinación de clorofila y CHN}

Las clorofilas $a$ y $b$ fueron extraidas en N,N-dimetilformamida (DMF) según Inskeep y Bloom (1985). Las muestras de tejido $\left(2.5 \mathrm{~cm}^{2}, n=6\right)$ se incubaron en la oscuridad en $3 \mathrm{~mL}$ de DMF a $4{ }^{\circ} \mathrm{C}$ durante $24 \mathrm{~h}$. La absorbancia se determinó con un espectrofotómetro y la concentración de clorofila se estimó con las ecuaciones porpuestas por Porra et al. (1989).

Después del periodo de incubación, las muestras se secaron a $60^{\circ} \mathrm{C}$ hasta obtener un peso constante. Los contenidos 
dissolved inorganic carbon) at $15^{\circ} \mathrm{C}$ in $5-\mathrm{mL}$ jacketed chambers connected to a water-circulating bath after a $0.5 \mathrm{~h}$ preincubation in darkness. Halogen lamps (Quartzline, $150 \mathrm{~W}$ ) were used as a light source, and photosynthetic photon flux was varied from 0 to $600 \mu \mathrm{mol}$ photon $\mathrm{m}^{-2} \mathrm{~s}^{-1}$ using neutral-density filters (Lee Filters, UK). Maximum oxygenic photosynthesis $\left(\mathrm{P}_{\max }\right)$, the initial slope of the photosynthesis $v s$ irradiance curve $\left(\alpha_{\text {oxy }}\right)$, the threshold for irradiance-saturated photosynthesis $\left(\mathrm{E}_{\mathrm{k}}\right)$, and respiration were determined by adjusting the data to the exponential equation (Sigma Plot, Jandel Scientific) described by Webb et al. (1974). GPS was calculated by adding net photosynthesis and respiration measured after each irradiance period.

In vivo chlorophyll fluorescence of PSII was determined $(n=6)$ with a portable pulse amplitude modulated fluorometer (Diving PAM, Walz, Germany). Basal fluorescence $\left(F_{o}\right)$ was determined after maintaining the tissue in darkness for $1-2 \mathrm{~h}$. A saturating actinic light pulse $\left(9000 \mu \mathrm{mol}\right.$ photon $\mathrm{m}^{-2}$ $\mathrm{s}^{-1}, 800 \mathrm{~ms}$ ) was applied to obtain maximum fluorescence $\left(F_{m}\right)$ in the dark-acclimated samples. Variable fluorescence $\left(F_{v}\right)$ was determined as the difference between $F_{m}$ and $F_{o}$, and optimum quantum yield was calculated as the ratio of $F_{v}$ to $\mathrm{F}_{\mathrm{m}}$ (Schreiber et al. 1994). The effective quantum yield of PSII $\left(\Phi_{\text {PSII }}\right)$ was determined in light-acclimated tissue according to Schreiber and Neubauer (1990):

$$
\Phi_{\text {PSII }}=\left(F_{m}^{\prime}-F_{t}\right) / F_{m}^{\prime}
$$

where $\mathrm{F}_{\mathrm{m}}^{\prime}$ is the maximal fluorescence of light-acclimated tissue induced by a saturating actinic light pulse $(9000 \mu \mathrm{mol}$ photon $\mathrm{m}^{-2} \mathrm{~s}^{-1}, 800 \mathrm{~ms}$ ), and $F_{t}$ is the intrinsic steady-state fluorescence in light-acclimated tissue. The optic fiber of the PAM fluorometer was kept at a $45^{\circ}$ angle from the tissue.

ETR was determined according to the following formula:

$$
\operatorname{ETR}\left(\mu \mathrm{mol} \text { electrons } \mathrm{m}^{-2} \mathrm{~s}^{-1}\right)=\mathrm{AQ} \lambda \cdot \mathrm{F}_{\mathrm{II}} \cdot \Phi_{\mathrm{PSII}}
$$

where $A Q \lambda$ is the absorbed photons calculated as the product of the integration of the spectral absorptance $\left(\mathrm{A}_{\lambda}\right)$ between $400-700 \mathrm{~nm}$ and spectral irradiance of the light source $\left(\mathrm{E}_{\lambda}\right)$, $\mathrm{F}_{\mathrm{II}}$ is the fraction of AQ directed to PSII including its lightharvesting complexes, and $\Phi_{\text {PSII }}$ is the effective quantum yield or quantum yield of PSII charge separation. Values of $\mathrm{F}_{\mathrm{II}}$ for different pigment groups can be estimated by determining the fraction of chlorophyll $a$ associated with PSII and its corresponding light-harvesting complexes (Grzymski et al. 1997). For example, $F_{\text {II }}$ values are approximately 0.5 for Chlorophyta and vascular plants (Grzymski et al. 1997, Figueroa et al. 2003).

Tissue absorptance $\left(\mathrm{A}_{\lambda}, n \geq 6\right)$ was determined at 1-nm intervals between 400 and $700 \mathrm{~nm}$ using an integrating sphere (LICOR-1802) connected to a spectroradiometer de carbono y nitrógeno intracelular total $(\mathrm{g} / \mathrm{g})$ se determinaron $(n=6)$ en un analizador elemental (PerkinElmer 2400 CHN).

\section{Evolución del oxígeno y fluorescencia de la clorofila}

Las tasas fotosintéticas en los haces de C. nodosa se determinaron mediante las tasas de evolución de $\mathrm{O}_{2}$ en estado estacionario (Rank Brothers, RU). El tejido $(\sim 0.2 \mathrm{~g}$ PF, $n=6)$ se incubó en agua de mar $(2.2 \mathrm{mM}$ de carbono inorgánico disuelto) a $15^{\circ} \mathrm{C}$ en cámaras de $5 \mathrm{~mL}$ conectadas a un baño de agua circulante después de un periodo de $0.5 \mathrm{~h}$ de preincubación en la oscuridad. Se usaron lámparas halógenas (Quartzline, $150 \mathrm{~W}$ ) como fuente de luz, y el flujo de fotones fotosintéticos se varió de 0 a $600 \mu \mathrm{mol}$ fotón $\mathrm{m}^{-2} \mathrm{~s}^{-1}$ con filtros de densidad neutra (Lee Filters, RU). La fotosíntesis oxigénica máxima $\left(\mathrm{P}_{\max }\right)$, la pendiente inicial de la curva fotosíntesis $v s$ irradiancia $\left(\alpha_{o x i}\right)$, el umbral para la fotosíntesis saturada por irradiancia $\left(\mathrm{E}_{\mathrm{k}}\right)$ y la respiración se determinaron mediante un ajuste de los datos a la ecuación exponencial (Sigma Plot, Jandel Scientific) descrita por Webb et al. (1974). La FB se calculó sumando la fotosíntesis neta y la respiración medida después de cada periodo de irradiación.

La fluorescencia in vivo de la clorofila del PSII se determinó $(n=6)$ con un fluorímetro de pulso de amplitud moderada portátil (Diving PAM, Walz, Alemania). La fluorescencia basal $\left(\mathrm{F}_{\mathrm{o}}\right)$ se determinó después de mantener el tejido en la oscuridad durante 1-2 h. Se aplicó un pulso de saturación de luz actínica (9000 $\mu \mathrm{mol}$ fotón $\left.\mathrm{m}^{-2} \mathrm{~s}^{-1}, 800 \mathrm{~ms}\right)$ para obtener la máxima fluorescencia $\left(\mathrm{F}_{\mathrm{m}}\right)$ en las muestras aclimatadas en la oscuridad. La fluorescencia variable $\left(F_{v}\right)$ se determinó como la diferencia entre $\mathrm{F}_{\mathrm{m}}$ y $\mathrm{F}_{\mathrm{o}}$, y el rendimineto cuántico óptimo se calculó como la razón de $F_{v}$ a $F_{m}$ (Schreiber et al. 1994). El rendimiento cuántico óptimo del PSII ( $\left.\Phi_{\mathrm{PSII}}\right)$ se determinó en el tejido expuesto a la luz según Schreiber y Neubauer (1990):

$$
\Phi_{\text {PSII }}=\left(F_{m}^{\prime}-F_{t}\right) / F_{m}^{\prime}
$$

donde $\mathrm{F}_{\mathrm{m}}^{\prime}$ es la fluorescencia máxima de tejido aclimatado con luz inducida mediante un pulso de saturación de luz actínica ( $9000 \mu \mathrm{mol}$ fotón $\mathrm{m}^{-2} \mathrm{~s}^{-1}, 800 \mathrm{~ms}$ ), y $\mathrm{F}_{\mathrm{t}}$ es la fluorescencia intrínseca en estado estacionario de tejido aclimatado con luz. Se mantuvo la fibra óptica del fluorímetro de PAM a un ángulo de $45^{\circ}$ del tejido.

La TTE se determinó con la siguiente ecuación:

$$
\text { TTE }\left(\mu \text { mol electrones } \mathrm{m}^{-2} \mathrm{~s}^{-1}\right)=\mathrm{AQ} \lambda \cdot \mathrm{F}_{\mathrm{II}} \cdot \Phi_{\mathrm{PSII}}
$$

donde AQ $\lambda$ representa los fotones absorbidos calculados como el producto de la integración de la absorptancia espectral $\left(A_{\lambda}\right)$ entre $400-700 \mathrm{~nm}$ y la irradiancia espectral de la fuente de luz $\left(\mathrm{E}_{\lambda}\right), \mathrm{F}_{\mathrm{II}}$ es la fracción de $\mathrm{AQ}$ dirigida al PSII 
(LICOR-1800 UW) according to the following formula (Schreiber and Neubauer 1990):

$$
\mathrm{A}_{\lambda}=1-\mathrm{T}_{\lambda}-\mathrm{R}_{\lambda}
$$

where $T_{\lambda}$ is transmittance and $R_{\lambda}$ is reflectance of the tissue.

Simultaneous measurements of oxygen evolution and $\Phi_{\text {PSII }}$ were conducted by introducing the PAM's optic fiber into the oxygen chamber. The optic fiber was placed at a $45^{\circ}$ angle with respect to the shoot tissue. Values for $\Phi_{\mathrm{PSII}}$ were determined after achieving steady oxygen evolution (approximately $5 \mathrm{~min}$ ) at each experimental irradiance. Irradiance was increased using neutral density filters after a $10 \mathrm{~min}$ period of darkness.

\section{Data analysis}

Differences in effective quantum yield, chlorophyll levels, absorptance, $\mathrm{P}_{\max }, \alpha_{\text {oxy }}, \mathrm{E}_{\mathrm{k}}$, respiration, and the GPS to respiration ratio (GPS/R) as a function of nitrate treatment were evaluated using a one-way analisis of variance after testing for normality and homoscedasticity of the data (Sokal and Rohlf 1995). All pairwise multiple comparisons were conducted using Tukey's test. The correlation significance between seawater nitrate concentration, tissue carbon, tissue nitrogen, carbon to nitrogen ratios $(\mathrm{C} / \mathrm{N})$, effective quantum yield, GPS, and ETR values was tested using Pearson's product moment correlations. Minimum significance level was established at $P<0.05$.

\section{RESULTS}

Carbon and nitrogen concentrations in C. nodosa tissue varied in relation to the nitrate incubation treatment (fig. 1). There was an increasing trend of carbon levels in the tissue from $38.6 \pm 1.6 \%$ in shoots incubated at $0 \mu \mathrm{M} \mathrm{NO}_{3}{ }^{-}$to $41.1 \pm$ $1.7 \%$ in shoots incubated at $100 \mu \mathrm{M} \mathrm{NO}_{3}^{-}$; however, there were no statistical differences among treatments $(P>0.05$, fig. 1a). Nitrogen levels in the tissue increased linearly from $2.1 \pm 1.7 \%$ in shoots incubated at $0 \mu \mathrm{M} \mathrm{NO}_{3}{ }^{-}$to $3.4 \pm 0.6 \%$ in shoots incubated at $100 \mu \mathrm{M} \mathrm{NO}_{3}^{-}(P<0.05$, fig. 1b). While carbon levels increased $6.5 \%$, nitrogen levels in the tissue augmented more than $60 \%$ when nitrate in the medium increased from 0 to $100 \mu \mathrm{M}$. There was a $30 \%$ decrease in the $\mathrm{C} / \mathrm{N}$ ratio in the tissue when nitrate in the medium increased from 0 to $100 \mu \mathrm{M}(P<0.05$, fig. $1 \mathrm{c})$.

Chlorophyll $a+b$ levels in tissue of $C$. nodosa fluctuated as a function of nitrate levels in the seawater (fig. 2a). The lowest chlorophyll levels $\left(0.64 \pm 0.12 \mathrm{mg} \mathrm{g}^{-1} \mathrm{FW}\right)$ were found in shoots incubated at $0 \mu \mathrm{M} \mathrm{NO}_{3}^{-}$, and chlorophyll levels saturated $\left(0.89 \pm 0.11 \mathrm{mg} \mathrm{g}^{-1} \mathrm{FW}\right)$ in shoots exposed to nitrate levels between 25 and $100 \mu \mathrm{M}$. Chlorophyll levels were approximately $30 \%$ greater $(P<0.05)$ in shoots exposed to $25-100 \mu \mathrm{M} \mathrm{NO}_{3}^{-}$than in shoots exposed incluyendo sus complejos de recolección de luz, y $\Phi_{\mathrm{PSII}}$ es el rendimiento cuántico efectivo o el rendimiento cuántico de la separación de carga del PSII. Es posible estimar los valores de $\mathrm{F}_{\text {II }}$ para diferentes grupos de pigmentos mediante la determinación de la fracción de clorofila $a$ asociada con el PSII y sus complejos de recolección de luz correspondientes (Grzymski et al. 1997). Por ejemplo, los valores de $F_{\text {II }}$ son aproximadamente 0.5 para Chlorophyta y plantas vasculares (Grzymski et al. 1997, Figueroa et al. 2003).

La absorptancia del tejido $\left(\mathrm{A}_{\lambda}, n \geq 6\right)$ se determinó a intervalos de $1 \mathrm{~nm}$ entre 400 y $700 \mathrm{~nm}$ con una esfera de integración (LICOR-1802) conectada a un espectroradiómetro (LICOR-1800 UW) según la siguiente fórmula (Schreiber y Neubauer 1990):

$$
\mathrm{A}_{\lambda}=1-\mathrm{T}_{\lambda}-\mathrm{R}_{\lambda}
$$

donde $T_{\lambda}$ es la transmitancia y $R_{\lambda}$ es la reflectancia del tejido.

Para realizar mediciones simultáneas de la evolución del oxígeno y el $\Phi_{\mathrm{PSII}}$, la fibra óptica del fluorímetro de PAM se introdujo en la cámara de oxígeno. La fibra óptica se colocó a un ángulo de $45^{\circ}$ con relación al tejido. Los valores para $\Phi_{\text {PSII }}$ se determinaron después de obtener una evolución de oxígeno constante (aproximadamente $5 \mathrm{~min}$ ) a cada irradiancia experimental. La irradiancia se incrementó usando filtros de densidad neutra después de un periodo de $10 \mathrm{~min}$ en la oscuridad.

\section{Análisis de datos}

Se evaluaron las diferencias en cuanto al rendimiento cuántico efectivo, los niveles de clorofila, la absorptancia, $\mathrm{P}_{\max }, \alpha_{o x i}, E_{k}$, la respiración y la razón $\mathrm{FB} /$ respiración $(\mathrm{FB} / \mathrm{R})$ en función del tratamiento de nitrato mediante un análisis de varianza de una vía después de comprobar la normalidad y homocedasticidad de los datos (Sokal y Rohlf 1995). Todas las comparaciones múltiples por pares se realizaron con la prueba de Tukey. Se usó el coeficiente de correlación producto-momento de Pearson para evaluar la significancia entre los valores de FB, TTE, la concentración de nitrato del agua de mar, el contenido de carbono y nitrógeno en el tejido, la razón carbono/nitrógeno $(\mathrm{C} / \mathrm{N})$ y el rendimiento cuántico efectivo. El nivel mínimo de significancia se estableció en $P<0.05$.

\section{RESUltados}

Las concentraciones de carbono y nitrógeno en el tejido de $C$. nodosa variaron con relación al nivel de nitrato en el medio de incubación (fig. 1). Los niveles de carbono en el tejido incrementaron de $38.6 \pm 1.6 \%$ a $41.1 \pm 1.7 \%$ en las plantas incubadas a 0 y $100 \mu \mathrm{M}$ de $\mathrm{NO}_{3}^{-}$, respectivamente; sin embargo, no se observaron diferencias entre los tratamientos $(P>0.05$, fig. 1a). Los niveles de nitrógeno en el 

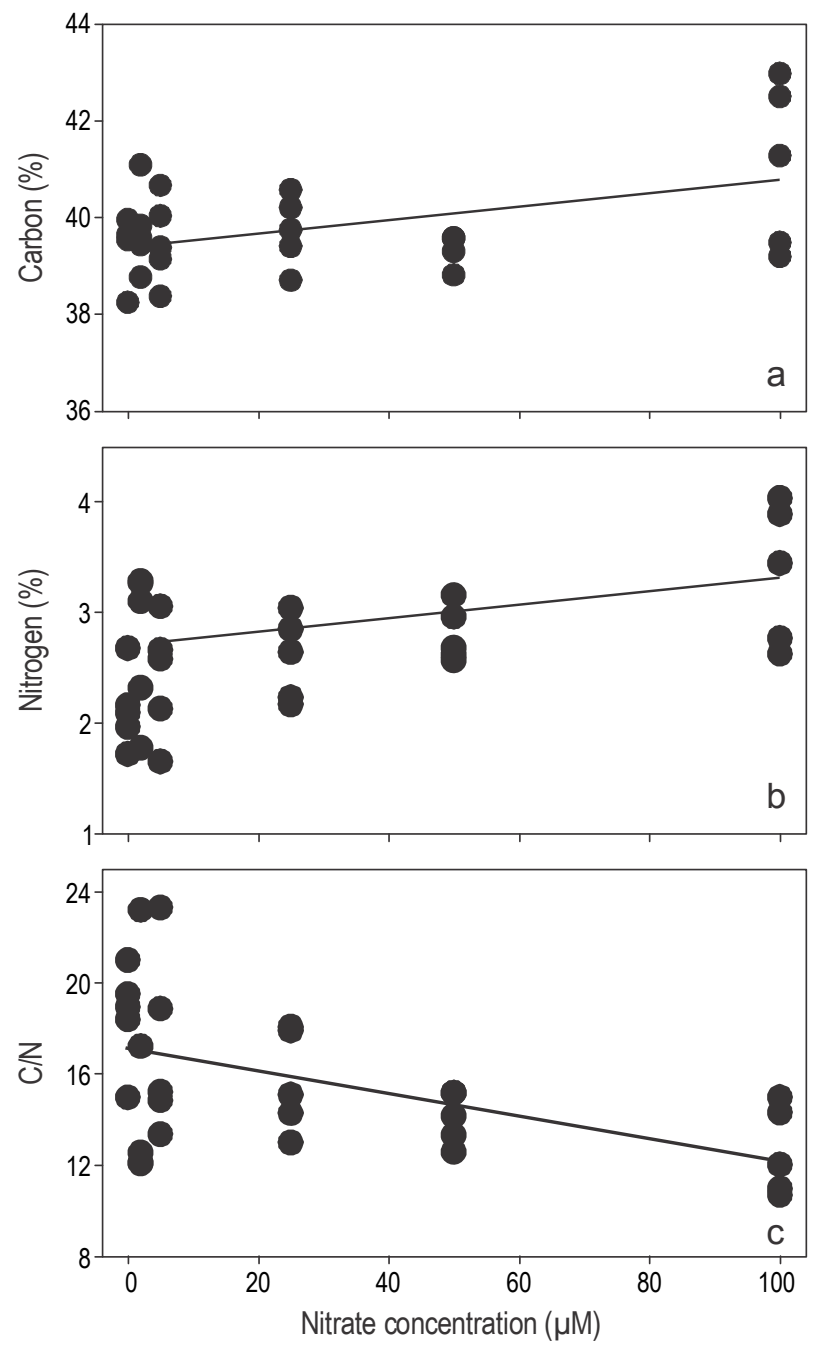

Figure 1. Carbon concentration (a), nitrogen concentration (b), and carbon to nitrogen ratio $(\mathrm{C} / \mathrm{N})(\mathbf{c})$ in the tissue of Cymodocea nodosa incubated at different nitrate levels.

Figura 1. Concentración de carbono (a), concentración de nitrógeno (b) y la razón carbono/nitrógeno $(\mathrm{C} / \mathrm{N})(\mathbf{c})$ en el tejido de la fanerógama marina Cymodocea nodosa incubada a diferentes niveles de nitrato.

to $0 \mu \mathrm{M} \mathrm{NO}{ }_{3}^{-}$. Similar to chlorophyll contents, tissue absorptance fluctuated as a function of nitrate concentration in the seawater (fig. 2b). The lowest absorptance levels $(0.65 \pm 0.05, P<0.05)$ were observed in shoots incubated at $0-5 \mu \mathrm{M} \mathrm{NO}_{3}{ }^{-}$and absorptance saturated $(0.74 \pm 0.01)$ in those incubated at $25-100 \mu \mathrm{M} \mathrm{NO}_{3}^{-}$.

Maximum rates of oxygen evolution and electron transport in C. nodosa in general increased as a function of nitrate availability. In general, $\mathrm{O}_{2}$-based photosynthesis was saturated at lower irradiances relative to ETR (fig. 3). Values of $\mathrm{P}_{\max }$ augmented by $25 \%$ when nitrate in the medium increased from $0 \mu \mathrm{M}$ to more than $25 \mu \mathrm{M}(P<0.05$, fig. $4 \mathrm{a})$. Except for $\mathrm{ETR}_{\max }$ values for shoots incubated at $50 \mu \mathrm{M}$ $\mathrm{NO}_{3}^{-}, \mathrm{ETR}_{\max }$ values increased $(P<0.05)$ when nitrate in the
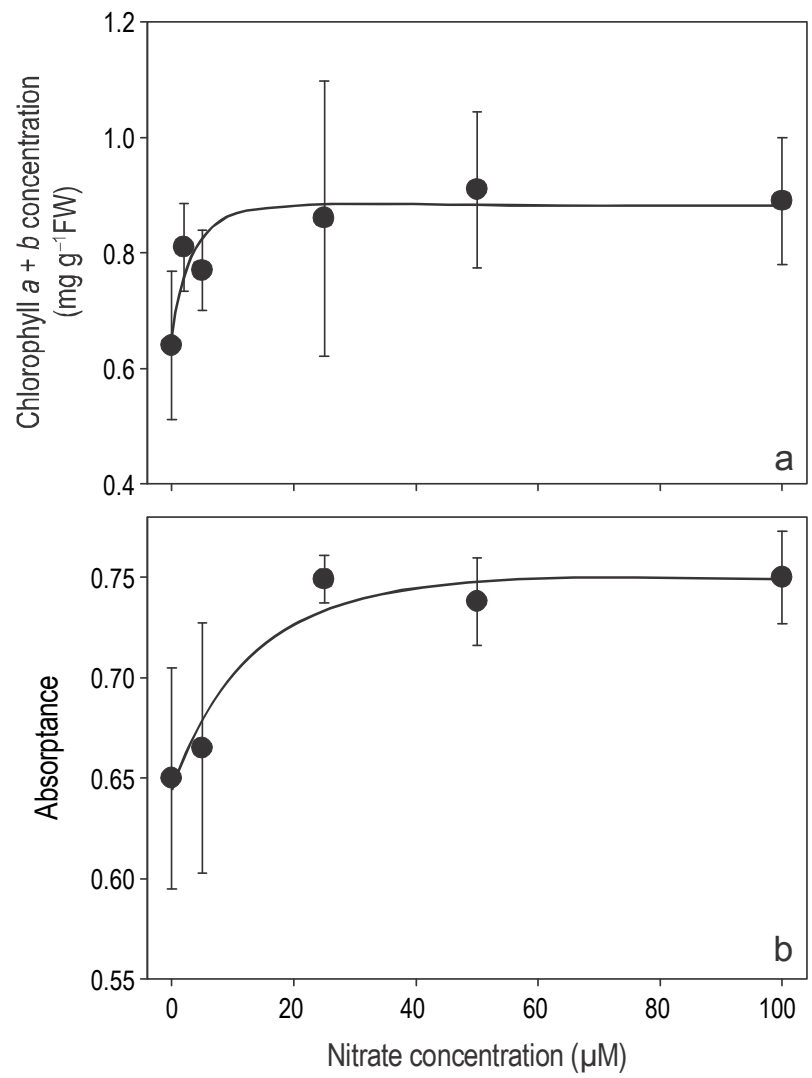

Figure 2. Chlorophyll $a+b$ concentration (a) and absorptance (b) in the tissue of Cymodocea nodosa incubated at different nitrate levels. Data points indicate the average of six samples \pm standard deviation.

Figura 2. Concentración de clorofila $a+b$ (a) y absorptancia (b) en el tejido de la fanerógama marina Cymodocea nodosa incubada a diferentes niveles de nitrato. Los puntos de datos indican el promedio de seis muestras \pm desviación estándar.

tejido aumentaron linealmente desde $2.1 \pm 1.7 \%$ en las plantas incubadas a $0 \mu \mathrm{M}$ de $\mathrm{NO}_{3}{ }^{-}$hasta $3.4 \pm 0.6 \%$ en las plantas incubadas a $100 \mu \mathrm{M}$ de $\mathrm{NO}_{3}^{-}(P<0.05$, fig. 1b). Mientras que los niveles de carbono incrementaron $6.5 \%$, los niveles de nitrógeno en el tejido aumentaron más de $60 \%$ cuando el nivel de nitrato en el medio aumentó de 0 a $100 \mu \mathrm{M}$. La razón $\mathrm{C} / \mathrm{N}$ en el tejido disminuyó $30 \%$ cuando el nivel de nitrato en el medio aumentó de 0 a $100 \mu \mathrm{M}(P<0.05$, fig. 1 c $)$.

Los niveles de clorofila $a+b$ en el tejido de $C$. nodosa fluctuaron en función de los niveles de nitrato en el agua de mar (fig. 2a). Las menores concentraciones de clorofila $\left(0.64 \pm 0.12 \mathrm{mg} \mathrm{g}^{-1} \mathrm{PF}\right)$ se encontraron en las plantas incubadas a $0 \mu \mathrm{M}$ de $\mathrm{NO}_{3}^{-}$y se registraron valores de saturación $\left(0.89 \pm 0.11 \mathrm{mg} \mathrm{g}^{-1} \mathrm{PF}\right)$ cuando el nivel de nitrato en el medio fue de 25 a $100 \mu \mathrm{M}$. Los niveles de clorofila fueron aproximadamente $30 \%$ mayores $(P<0.05)$ en las plantas expuestas a $25-100 \mu \mathrm{M}$ de $\mathrm{NO}_{3}{ }^{-}$que en las plantas expuestas a $0 \mu \mathrm{M}$ de $\mathrm{NO}_{3}^{-}$. De manera similar, la absorptancia del tejido varió en función de la concentración de nitrato en el agua de mar 
medium increased (fig. 4a). The initial slope of oxygen evolution $\left(\alpha_{\text {oxy }}\right)$ increased $(P<0.05)$ from approximately $15 \mathrm{nmol} \mathrm{O}_{2} \mathrm{gFW}^{-1} \mathrm{~min}^{-1}$ ( $\mu \mathrm{mol}$ photon $\left.\mathrm{m}^{-2} \mathrm{~s}^{-1}\right)^{-1}$ in shoots with $0-5 \mu \mathrm{M} \mathrm{NO}_{3}^{-}$in the medium to approximately $25 \mathrm{nmol}$ $\mathrm{O}_{2} \mathrm{gFW}^{-1} \mathrm{~min}^{-1}$ ( $\mu$ mol photon $\left.\mathrm{m}^{-2} \mathrm{~s}^{-1}\right)^{-1}$ in shoots incubated at $25-50 \mu \mathrm{M} \mathrm{NO}_{3}^{-}$. In contrast to $\alpha_{\text {oxy }}$, the lowest values of $\alpha_{\text {ETR }}$ $\left(0.28 \pm 0.03 \mu \mathrm{mol} e^{-} \mathrm{m}^{-2} \mathrm{~s}^{-1} \text { ( } \mu \text { mol photon } \mathrm{m}^{-2} \mathrm{~s}^{-1}\right)^{-1}$; $P<0.05$ ) were observed in shoots incubated at $0 \mu \mathrm{M} \mathrm{NO}_{3}^{-}$; however, values saturated at approximately $0.43 \pm 0.03$ in shoots incubated at 2-100 $\mu \mathrm{M} \mathrm{NO}_{3}{ }^{-}$(fig. $4 \mathrm{~b}$ ). Values of $\mathrm{E}_{\mathrm{k}}$ were approximately four-fold greater $(P<0.05)$ when determined by fluorimetric methods than when determined by oxygenic methods. Oxygenic $E_{k}$ values remained relatively constant $\left(25-30 \mu \mathrm{mol}\right.$ photon $\left.\mathrm{m}^{-2} \mathrm{~s}^{-1}\right)$, whereas fluorimetric $\mathrm{E}_{\mathrm{k}}$ values decreased from approximately $120-130 \mu \mathrm{mol}$ photon $\mathrm{m}^{-2} \mathrm{~s}^{-1}$ in shoots incubated at $0-25 \mu \mathrm{M}$ $\mathrm{NO}_{3}^{-}$to $67-98 \mu \mathrm{mol}$ photon $\mathrm{m}^{-2} \mathrm{~s}^{-1}$ in shoots incubated at $50-100 \mu \mathrm{M} \mathrm{NO}_{3}^{-}$(fig. 4c).

GPS and ETR followed a linear relationship only in tissue incubated at 50 and $100 \mu \mathrm{M} \mathrm{NO}_{3}^{-}$(fig. 5). The GPS-ETR relationship deviated from the linear relationship in shoots with $0-25 \mu \mathrm{M} \mathrm{NO}_{3}{ }^{-}$in the medium, especially at high irradiances. In general, values showed little deviation from a linear model at irradiances below $100 \mu \mathrm{mol}$ photon $\mathrm{m}^{-2} \mathrm{~s}^{-1}$ and deviation increased when tissues were incubated at irradiances above $300 \mu \mathrm{mol}$ photon $\mathrm{m}^{-2} \mathrm{~s}^{-1}$. Deviation of the data from the linear model at high irradiances decreased as nitrate concentration increased in the treatments.

Respiration rates increased from approximately $44 \pm$ $31 \mathrm{nmol} \mathrm{O}_{2} \mathrm{gFW}^{-1} \mathrm{~s}^{-1}$ in shoots incubated at $0 \mu \mathrm{M} \mathrm{NO}_{3}{ }^{-}$to saturation values of $129 \pm 34 \mathrm{nmol} \mathrm{O}_{2} \mathrm{gFW}^{-1} \mathrm{~s}^{-1}$ in tissue incubated at $25-50 \mu \mathrm{M} \mathrm{NO}_{3}{ }^{-}$(fig. $6 \mathrm{a}, P<0.05$ ). There was a three-fold increase in respiration rates as nitrate concentration augmented from 0 to $25-100 \mu \mathrm{M}$. The GPS/R ratio decreased $(P<0.05)$ from $7.3 \pm 1.4$ in shoots incubated at $0 \mu \mathrm{M} \mathrm{NO}_{3}{ }^{-}$to $3.1 \pm 0.8$ in shoots incubated at $50-100 \mu \mathrm{M}$ $\mathrm{NO}_{3}^{-}$(fig. 6b). The rapid decline in the GPS/R ratio was promoted by the rapid increase in respiration rate as nitrogen augmented in the medium, relative to the increase in GPS.

\section{DisCUSSION}

In this study we demonstrate that chlorophyll concentration, absorptance, $\mathrm{C} / \mathrm{N}$ ratios, optimum quantum yield, and GPS/R ratios in C. nodosa tissue are regulated by nitrate availability in the culture medium. Secondly, we demonstrate that the GPS-ETR relationship also depends on the nitrogen concentration in the tissue of $C$. nodosa. Similar findings have been reported for marine macroalgae such as Ulva rigida (Cabello-Pasini and Figueroa 2005), where nitrate concentration in the medium regulated oxygenic and fluorimetric photosynthesis as well as the GPS-ETR relationship.

The levels of external and internal nitrogen contents appear to play a critical role in tissue chlorophyll levels
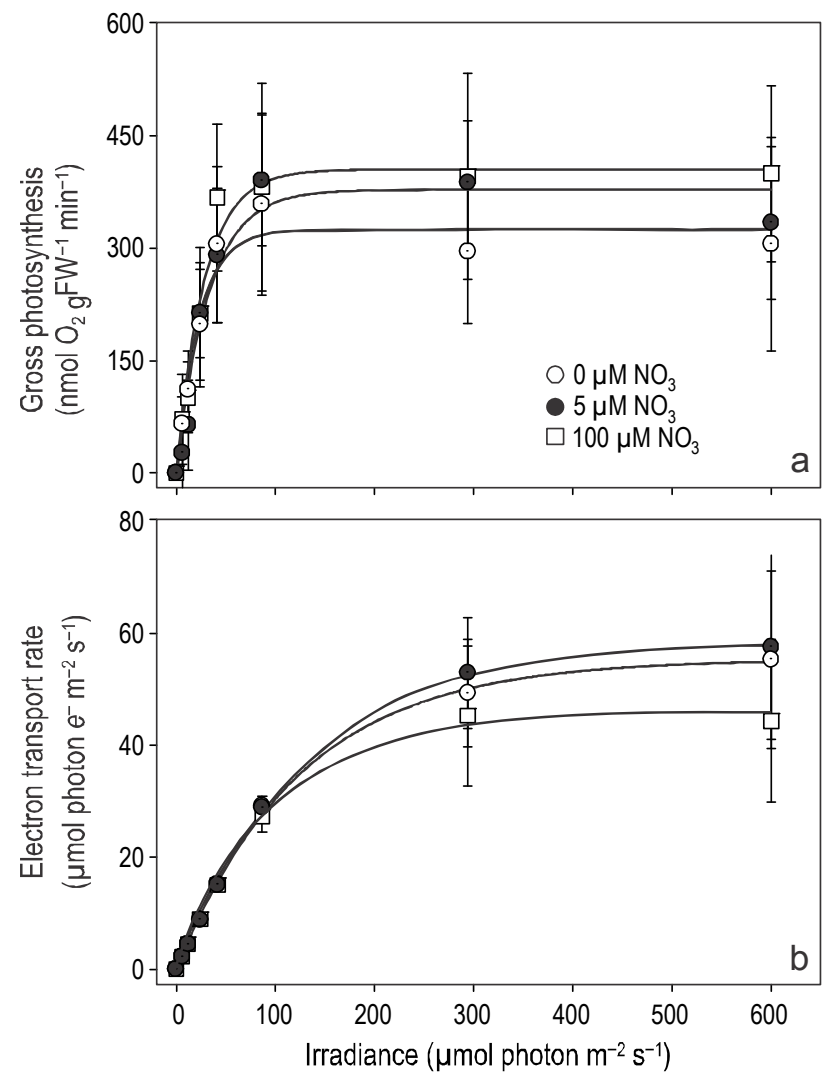

Figure 3. Relationship between gross photosynthesis and irradiance (a) and between electron transport rate and irradiance (b) in Cymodocea nodosa incubated at different nitrate levels. Data points indicate the average of six samples \pm standard deviation. Error bars not shown are smaller than symbol size.

Figura 3. Relación entre la fotosíntesis bruta y la irradiancia (a) y entre la tasa de transporte electrónico y la irradiancia (b) en la fanerógama marina Cymodocea nodosa incubada a diferentes niveles de nitrato. Los puntos de datos indican el promedio de seis muestras \pm desviación estándar. Las barras de error que no se muestran son menores que el tamaño del símbolo.

(fig. 2b). Los menores niveles de absorptancia $(0.65 \pm 0.05$, $P<0.05)$ se observaron en las plantas incubadas a $0-5 \mu \mathrm{M}$ de $\mathrm{NO}_{3}{ }^{-}$y se observó saturación $(0.74 \pm 0.01)$ en las plantas incubadas a $25-100 \mu \mathrm{M}$ de $\mathrm{NO}_{3}^{-}$.

Las máximas tasas de evolución del oxígeno y transporte electrónico en C. nodosa en general aumentaron en función de la disponibilidad de nitrato. En general, la fotosíntesis oxigénica presentó saturación a menores irradiancias en relación con la TTE (fig. 3). Los valores de $\mathrm{P}_{\max }$ incrementaron $25 \%$ cuando el nitrato en el medio aumentó de $0 \mu \mathrm{M}$ a más de $25 \mu \mathrm{M}(P<0.05$, fig. 4a). Con excepción de los valores de $\mathrm{TTE}_{\max }$ para las plantas incubadas a $50 \mu \mathrm{M}$ de $\mathrm{NO}_{3}^{-}$, los valores de $\mathrm{TTE}_{\max }$ incrementaron $(P<0.05)$ al aumentar el nitrato del medio (fig. 4a). La pendiente inicial de la evolución del oxígeno $\left(\alpha_{\text {oxi }}\right)$ aumentó $(P<0.05)$ desde aproximadamente $15 \mathrm{nmol} \mathrm{O}_{2} \mathrm{gPF}^{-1} \min ^{-1}\left(\left[\mu \mathrm{mol} \text { fotón } \mathrm{m}^{-2} \mathrm{~s}^{-1}\right]^{-1}\right)$ en 

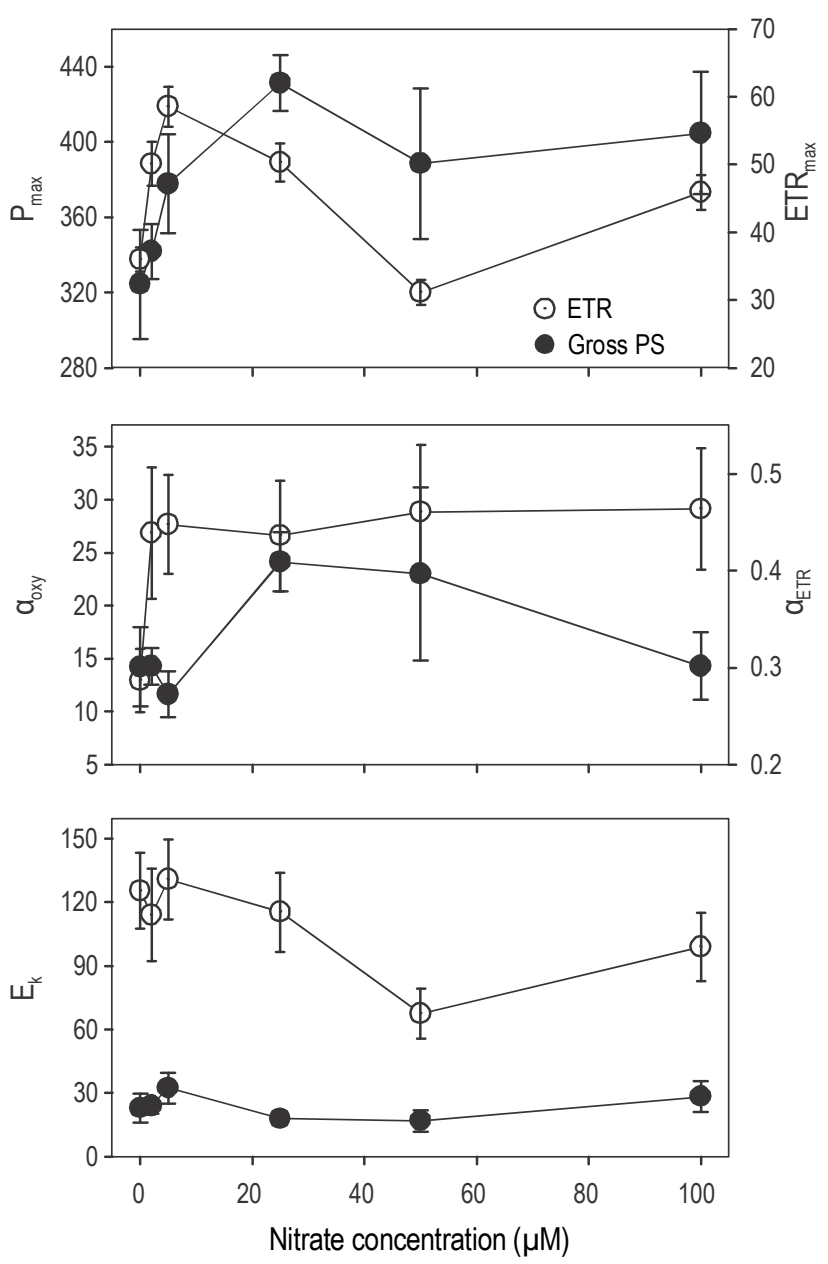

Figure 4. (a) Maximum oxygenic photosynthesis $\left(\mathrm{P}_{\max }, \mathrm{nmol} \mathrm{O}_{2}\right.$ $\left.\mathrm{gFW}^{-1} \min ^{-1}\right)$ and maximum electron transport rate $\left(\mathrm{ETR}_{\max }\right.$, $\left.\mu \mathrm{mol} \quad e^{-} \mathrm{m}^{-2} \mathrm{~s}^{-1}\right)$, (b) initial slope of the oxygenic photosynthesis $v$ s irradiance relationship $\left(\alpha_{\mathrm{OXY}}, \mathrm{nmol} \mathrm{O}_{2} \mathrm{gFW}^{-1}\right.$ $\min ^{-1}\left[\mu \mathrm{mol} \text { photon } \mathrm{m}^{-2} \mathrm{~s}^{-1}\right]^{-1}$ ) and initial slope of the electron transport rate $v s$ irradiance relationship $\left(\alpha_{\mathrm{ETR}}, \mu \mathrm{mol} e^{-} \mathrm{m}^{-2} \mathrm{~s}^{-1}\right.$ [ $\mu \mathrm{mol}$ photon $\left.\left.\mathrm{m}^{-2} \mathrm{~s}^{-1}\right]^{-1}\right)$, and (c) subsaturation coefficient $\left(\mathrm{E}_{\mathrm{k}}\right.$, $\mu$ mol photon $\mathrm{m}^{-2} \mathrm{~s}^{-1}$ ) for Cymodocea nodosa incubated at different nitrate levels. Data points indicate the average of six samples \pm standard deviation. Error bars not shown are smaller than symbol size.

Figura 4. (a) Fotosíntesis oxigénica máxima $\left(\mathrm{P}_{\max }, \mathrm{nmol} \mathrm{O}_{2}\right.$ $\left.\mathrm{gPF}^{-1} \min ^{-1}\right)$ y tasa de transporte electrónico máximo $\left(\mathrm{ETR}_{\max }\right.$, $\left.\mu \mathrm{mol} e^{-} \mathrm{m}^{-2} \mathrm{~s}^{-1}\right)$, (b) pendiente inicial de la relación fotosíntesis oxigénica $v s$ irradiancia $\left(\alpha_{\mathrm{OXY}}, \mathrm{nmol} \mathrm{O}_{2} \mathrm{gPF}^{-1} \mathrm{~min}^{-1}\right.$ [ $\mu$ mol fotón $\mathrm{m}^{-2} \mathrm{~s}^{-1} \mathrm{~J}^{-1}$ ) y pendiente inicial de la relación tasa de transporte electrónico vs irradiancia $\left(\alpha_{\mathrm{ETR}}, \mu \mathrm{mol} e^{-} \mathrm{m}^{-2} \mathrm{~s}^{-1}\right.$ [ $\mu \mathrm{mol}$ fotón $\mathrm{m}^{-2}$ $\left.\left.\mathrm{s}^{-1}\right]^{-1}\right)$ y (c) coeficiente de subsaturación $\left(\mathrm{E}_{\mathrm{k}}, \mu \mathrm{mol}\right.$ fotón $\left.\mathrm{m}^{-2} \mathrm{~s}^{-1}\right)$ para la fanerógama marina Cymodocea nodosa incubada a diferentes niveles de nitrato. Los puntos de datos indican el promedio de seis muestras \pm desviación estándar. Las barras de error que no se muestran son menores que el tamaño del símbolo. las plantas expuestas a $0-5 \mu \mathrm{M}$ de $\mathrm{NO}_{3}{ }^{-}$hasta aproximadamente $25 \mathrm{nmol} \mathrm{O}_{2} \mathrm{gPF}^{-1} \mathrm{~min}^{-1}$ ( $\left[\mu \mathrm{mol} \text { fotón } \mathrm{m}^{-2} \mathrm{~s}^{-1}\right]^{-1}$ ) en las plantas expuestas a $25-50 \mu \mathrm{M}$ de $\mathrm{NO}_{3}^{-}$. En contraste con $\alpha_{\text {oxi, }}$, los menores valores de $\alpha_{\mathrm{TTE}}\left(0.28 \pm 0.03 \mu \mathrm{mol} e^{-} \mathrm{m}^{-2} \mathrm{~s}^{-1}\right.$ $\left.\left[\mu \mathrm{mol} \text { fotón } \mathrm{m}^{-2} \mathrm{~s}^{-1}\right]^{-1} ; P<0.05\right)$ se registraron para las plantas expuestas a $0 \mu \mathrm{M}$ de $\mathrm{NO}_{3}^{-}$; sin embargo, se observó saturación a aproximadamente $0.43 \pm 0.03$ en las plantas incubadas a 2-100 $\mu \mathrm{M}$ de $\mathrm{NO}_{3}^{-}$(fig. 4b). Los valores de $\mathrm{E}_{\mathrm{k}}$ fueron aproximadamente cuatro veces mayores $(P<0.05)$ cuando se determinaron mediante métodos fluorimétricos que cuando se determinaron mediante métodos oxigénicos: los valores oxigénicos permanecieron relativamente constantes (25-30 $\mu \mathrm{mol}$ fotón $\left.\mathrm{m}^{-2} \mathrm{~s}^{-1}\right)$, mientras que los fluorimétricos disminuyeron desde aproximadamente 120-130 $\mu \mathrm{mol}$ fotón $\mathrm{m}^{-2} \mathrm{~s}^{-1}$ en las plantas incubadas a $0-25 \mu \mathrm{M}$ de $\mathrm{NO}_{3}{ }^{-}$ hasta 67-98 $\mu \mathrm{mol}$ fotón $\mathrm{m}^{-2} \mathrm{~s}^{-1}$ en las plantas incubadas a 50-100 $\mu \mathrm{M}$ de $\mathrm{NO}_{3}^{-}$(fig. 4c).

La FB y la TTE presentaron una relación lineal sólo en el caso del tejido expuesto a 50 y $100 \mu \mathrm{M} \mathrm{NO}_{3}^{-}$(fig. 5). La relación FB-TTE se desvió de una relación lineal cuando el nivel de nitrato en el medio fue de 0 a $25 \mu \mathrm{M}$, especialmente a altas irradiancias. En general, los valores mostraron poca desviación de un modelo lineal a irradiancias inferiores a $100 \mu \mathrm{mol}$ fotón $\mathrm{m}^{-2} \mathrm{~s}^{-1} \mathrm{y}$ la desviación aumentó cuando los tejidos fueron incubados a irradiancias superiores a $300 \mu \mathrm{mol}$ fotón $\mathrm{m}^{-2} \mathrm{~s}^{-1}$. La desviación de los datos del modelo lineal a altas irradiancias disminuyó conforme aumentó el nivel de nitrato en los tratamientos.

Las tasas de respiración incrementaron desde $\sim 44 \pm$ $31 \mathrm{nmol} \mathrm{O}_{2} \mathrm{gPF}^{-1} \mathrm{~s}^{-1}$ en el tejido incubado a $0 \mu \mathrm{M}$ de $\mathrm{NO}_{3}^{-}$ hasta valores de saturación de $129 \pm 34 \mathrm{nmol} \mathrm{O}_{2} \mathrm{gPF}^{-1} \mathrm{~s}^{-1}$ en el tejido incubado a $25-50 \mu \mathrm{M}$ de $\mathrm{NO}_{3}^{-}$(fig. $6 \mathrm{a}, \mathrm{P}<0.05$ ). Las tasas de respiración aumentaron tres veces cuando el nivel de nitrato aumentó de 0 a $25-100 \mu \mathrm{M}$. La razón $\mathrm{FB} / \mathrm{R}$ decreció $(P<0.05)$ desde $7.3 \pm 1.4$ en el tejido incubado a $0 \mu \mathrm{M}$ de $\mathrm{NO}_{3}^{-}$hasta $3.1 \pm 0.8$ en el tejido incubado a 50-100 $\mu \mathrm{M}$ de $\mathrm{NO}_{3}^{-}$(fig. 6b). La rápida disminución de la razón $\mathrm{FB} / \mathrm{R}$ fue resultado del rápido aumento de la tasa de respiración conforme aumentó el nitrógeno en el medio, con relación al aumento de la FB.

\section{DISCUSIÓN}

En el presente trabajo se demuestra que la absorptancia, las razones $\mathrm{C} / \mathrm{N}$, el rendimiento cuántico óptimo, las razones FB/R y la concentración de clorofila en el tejido de C. nodosa se regulan por la disponibilidad de nitrato en el medio de cultivo. Así mismo, se demuestra que la relación FB-TTE también depende de la concentración de nitrógeno en el tejido de C. nodosa. Estos resultados coinciden con lo documentado por Cabello-Pasini y Figueroa (2005), quienes encontraron que la concentración de nitrato en el medio reguló la fotosíntesis oxigénica y fluorimétrica, así como la relación FB-TTE en la macroalga marina Ulva rigida. 


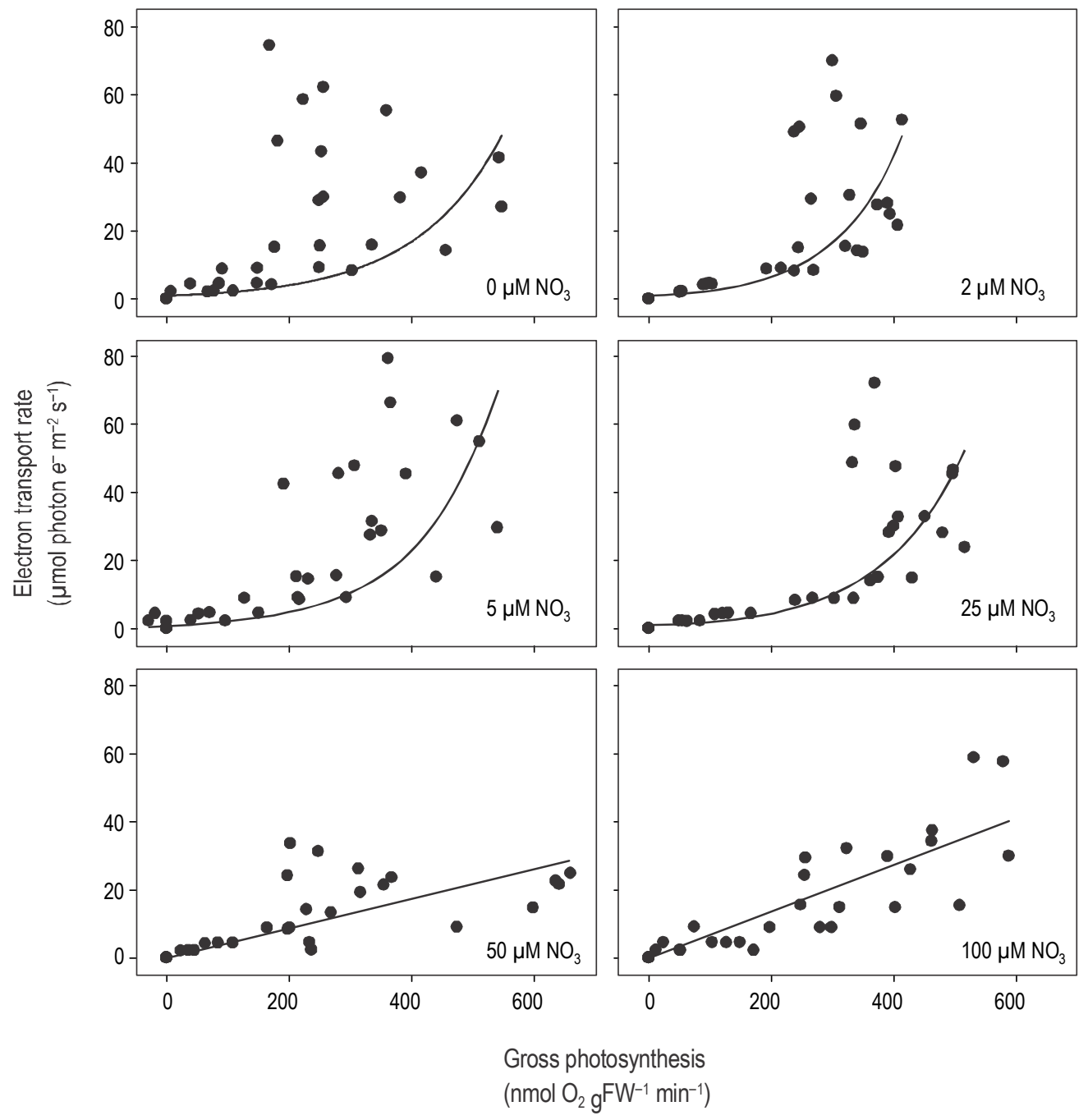

Figure 5. Relationship between electron transport rate (ETR) and oxygenic gross photosynthesis in Cymodocea nodosa incubated at different nitrate levels.

Figura 5. Relación entre la tasa de transporte electrónico (ETR) y la fotosíntesis oxigénica bruta en la fanerógama marina Cymodocea nodosa incubada a diferentes niveles de nitrato.

and absorptance of C. nodosa. Previous studies have demonstrated that chlorophyll levels in tissues of marine macrophytes can change within hours or days after a change in the nitrate concentration in the medium (Young and Beardall 2003, Cabello-Pasini et al. 2004, Cabello-Pasini and Figueroa 2005). These changes in chlorophyll levels are consistent with the observed increase in chlorophyll content in phytoplankton as a result of increasing levels of nitrogen in the medium (Young and Beardall 2003). Furthermore, changes in absorptance levels in the tissue of $C$. nodosa are likely the result of changes in chlorophyll levels as observed in other macrophyte species (Cabello-Pasini and Figueroa 2005).

In marine macrophytes, the ETR-GPS relationship has been shown to be species-specific and dependent on light
Los niveles de nitrógeno externo e interno parecen influir de manera importante en los niveles de clorofila y absorptancia en el tejido de $C$. nodosa. Estudios anteriores han mostrado que los niveles de clorofila en los tejidos de macrófitos marinos pueden cambiar dentro de horas o días después de un cambio en la concentración de nitrato en el medio (Young y Beardall 2003, Cabello-Pasini et al. 2004, Cabello-Pasini y Figueroa 2005). Estos cambios en los niveles de clorofila son consistentes con el aumento del contenido de clorofila observado en fitoplancton como resultado del incremento de los niveles de nitrógeno en el medio (Young y Beardall 2003). Además, los cambios en los niveles de absorptancia en el tejido de $C$. nodosa probablemente se deben a cambios en los niveles de clorofila, como ha sido observado en otras plantas aquáticas (Cabello-Pasini y Figueroa 2005). 
history, $\mathrm{CO}_{2}$ levels in the water, and the methods used to evaluate oxygen evolution and chlorophyll fluorescence (Beer and Bjork 2000, Franklin and Badger 2001, Gordillo et al. 2001, Carr and Bjork 2003, Figueroa et al. 2003, Beer and Axelsson 2004). Furthermore, the slope of the ETR-GPS relationship was observed to decrease in $U$. rigida as the nitrate concentration increased in the medium (CabelloPasini and Figueroa 2005). While Carr et al. (2003) observed that the relationship between ETR and GPS did not show a linear response in Ulva, findings by Cabello-Pasini and Figueroa (2005) show a linear relationship for the same genus. Our study suggests that the ETR-GPS relationship in C. nodosa deviates from a linear relationship only in tissue incubated at nitrogen levels below $25 \mu \mathrm{M}$. This suggests that at least in some plants, nitrogen concentration in tissues regulates the coupling of oxygen evolution and photon flux. It is also likely that an annual fluctuation of the ETR-GPS relationship will occur as a result of seasonal changes of nitrogen in the seawater or as a result of nutrient pulses such as those observed under upwelling conditions.

It has been demonstrated that under continuous light conditions, there is a general decrease in maximum ETR, which has been associated with an increase in the minimum requirements for $\mathrm{O}_{2}$ evolution (Herzig and Falkowski 1989). Furthermore, nitrogen limitation has been shown to regulate the photochemical efficiency of PSII during photochemical reactions, mainly due to an increase in thermal dissipation of absorbed excitation energy (Falkowski 1992). Such impact of nitrogen on the photochemical efficiency of PSII is similar to the photoinhibitory response observed in submerged aquatic vegetation. On the other hand, nitrogen limitation has also been observed to decrease respiratory rates, which in turn increase GPS/R ratios (Carr and Bjork 2003, Cabello-Pasini and Figueroa 2005). Respiration rates of $C$. nodosa decreased significantly as nitrogen levels in the medium decreased below $10 \mu \mathrm{M}$. This is consistent with previous findings where the addition of $\mathrm{NO}_{3}{ }^{-}$and $\mathrm{NH}_{4}{ }^{+}$, for example, resulted in a marked stimulation of dark respiration and dark carbon fixation in the microalga Selenastrum minutum (Elrifi and Turpin 1986). Apparently, decreases in protein synthesis (a major consequence of nitrogen limitation) reduce the demands for carbon skeletons and ATP in the respiratory pathway (Turpin 1991).

The ETR response in C. nodosa was found to be four- to ten-fold more variable than that observed in Ulva lactuca under low nitrate concentration (Carr and Bjork 2003, Cabello-Pasini and Figueroa 2005). Clearly, the dispersion of data of the ETR-GPS relationship increases as nitrogen in the medium and in tissue decreases. It is possible that the lower levels of chlorophyll in tissues incubated at low nitrate concentration could cause variability of the data. Absorptance also decreases and becomes more variable at low nitrate levels, suggesting that the absorbed light was not efficiently used for photochemistry. For example, photochemical efficiency decreases as a result of a lower number of

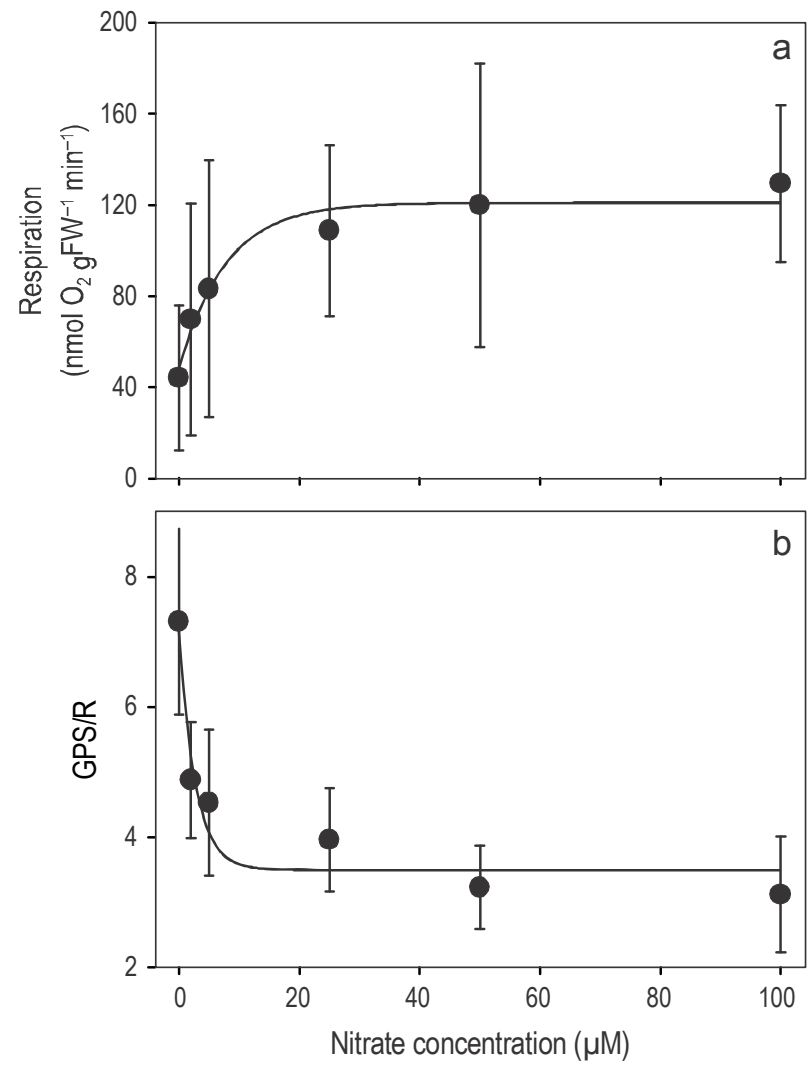

Figure 6. Respiration (a) and maximum gross photosynthesis/ respiration (GPS/R) ratio (b) of Cymodocea nodosa incubated at different nitrate levels. Data points indicate average of six samples \pm standard deviation.

Figura 6. Respiración (a) y razón fotosíntesis bruta máxima/ respiración (GPS/R) (b) de la fanerógama marina Cymodocea nodosa incubada a diferentes niveles de nitrato. Los puntos de datos indican el promedio de seis muestras \pm desviación estándar.

En los macrófitos marinos, la relación FB-TTE depende de la especie, así como del historial de luz, los niveles de $\mathrm{CO}_{2}$ en el agua y los métodos usados para evaluar la evolución del oxígeno y la fluorescencia de la clorofila (Beer y Bjork 2000, Franklin y Badger 2001, Gordillo et al. 2001, Carr y Bjork 2003, Figueroa et al. 2003, Beer y Axelsson 2004). En $U$.rigida, la pendiente de la relación FB-TTE decreció conforme aumentó la concentración de nitrato en el medio (Cabello-Pasini y Figueroa 2005). Según Carr et al. (2003), la relación FB-TTE no muestra una respuesta lineal en Ulva, pero los resultados de Cabello-Pasini y Figueroa (2005) muestran una relación lineal para el mismo género. El presente estudio sugiere que la relación FB-TTE en C. nodosa se desvía de una relación lineal sólo en el caso del tejido incubado a niveles de nitrógeno inferiores a $25 \mu \mathrm{M}$. Esto sugiere que al menos en algunas plantas, la concentración de nitrógeno en los tejidos regula el acoplamiento de la evolución del oxígeno y el flujo de fotones. También es posible que se produzca una fluctuación anual de la relación FB-TTE como resultado de los cambios estacionales en los 
functional PSII centers relative to antennae or because of an increase in the absorption cross-section of PSII, both which impact energy transfer between PSII reaction centers (Falkowski 1992).

The GPS-ETR relationship can vary in response to different nutrient sinks. In addition to carbon assimilation, other sinks, such as nitrogen assimilation, have been shown to regulate these ratios (Figueroa et al. 2003). The slopes of GPS vs ETR or $\Phi_{\text {PSII }} v s \Phi_{\mathrm{O} 2}$, for example, were lower in Ulva rotundata and Phorphyra leucosticta with the highest nitrogen assimilation capacity, estimated as nitrate reductase activity and internal nitrogen contents, relative to that observed in Ulva olivascens (Figueroa et al. 2003). As mentioned above, the basic assimilatory pathway for inorganic nitrogen is closely dependent on organic carbon and, hence, nitrogen limitation finally increases allocation of organic carbon to lipids and carbohydrates (Falkowski and Raven 1997). Babin et al. (1996) found maximum quantum yield of carbon fixation to roughly covary with the nitrate concentration in phytoplankton samples. In contrast, under nitrogen-enriched conditions (as in our study), the sudden nitrogen assimilation could inhibit RUBISCO activity and, consequently, electrons might be used for nitrate assimilation and the respiratory carbon flow would increase to provide carbon skeletons (Turpin 1991).

Overall, the $\mathrm{C} / \mathrm{N}$ ratios observed in C. nodosa fall within the range described for marine macrophytes (Atkinson and Smith 1983). In marine macrophytes, most of the organic carbon and nitrogen is found in structural components, which suggests that dark respiration is strongly related to biomass formation. Thus, it is possible that the decrease in the $\mathrm{C} / \mathrm{N}$ ratio with increasing nitrate levels in the medium might be the result of a transient suppression of photosynthetic carbon fixation due to a competition between the Calvin cycle and nitrogen assimilation. Whether other processes such as nitrogen storage ( $\mathrm{N}$ pools) and remobilization are active in Cymodocea is unclear and require further investigation.

This study demonstrates that the relationship between GPS and ETR is dependent on the nitrogen status in the tissue of $C$. nodosa. Nitrate availability also affected a number of parameters such as carbon, nitrogen, and chlorophyll content in the tissue as well as the absorptance of the tissue. Consequently, it is possible that the sample-to-sample variation within and among studies may be the result of the differences in tissue nitrogen levels. This study also suggests that the relationship between GPS and ETR in natural seagrass populations may vary as a result of natural fluctuations in nutrient loads (i.e., upwelling events).

\section{ACKNOWLEDGMENTS}

Financial support was provided by the Ministry of Education, Culture and Sports (AGL 2005-02655) and Junta de Andalucía (RNM-295), Spain. Alejandro Cabello-Pasini was supported by a grant from the Spanish Ministry of Education, Culture and Sports (SAB2002-0209). niveles de nitrógeno en el agua de mar o como resultado de pulsos de nutrientes como los observados durante los eventos de surgencia.

Se ha demostrado que en condiciones de luz continua, se presenta una disminución general de la TTE máxima, la cual ha sido relacionado con un aumento en los requerimientos mínimos para la evolución de $\mathrm{O}_{2}$ (Herzig y Falkowski 1989). Además, a nivel de reacciones fotoquímicas, se ha mostrado que la limitación de nitrógeno regula la eficiencia fotoquímica del PSII, principalmente debido a un incremento de la disipación térmica de la energía de excitación absorbida (Falkowski 1992). Tal impacto del nitrógeno en la eficiencia fotoquímica del PSII es similar a la respuesta fotoinhibidora observada en la vegetación acuática sumergida. Por otro lado, también se ha observado que la limitación de nitrógeno disminuye las tasas de respiración que a su vez incrementan las razones FB/R (Carr y Bjork 2003, Cabello-Pasini y Figueroa 2005). Las tasas de respiración de C. nodosa disminuyeron significativamente cuando los niveles de nitrógeno en el medio fueron inferiores a $10 \mu \mathrm{M}$. Esto coincide con resultados previos; por ejemplo, la adición de $\mathrm{NO}_{3}{ }^{-} \mathrm{y} \mathrm{NH}_{4}{ }^{+}$ resultó en una estimulación de la respiración en oscuridad y la fijación de carbono en oscuridad en la microalga Selenastrum minutum (Elrifi y Turpin 1986). Aparentemente, una disminución de la síntesis proteica (una consecuencia importante de la limitación de nitrógeno) reduce la demanda de esqueletos de carbono y ATP en la vía respiratoria (Turpin 1991).

La respuesta de la TTE en C. nodosa fue de tres a diez veces más variable que la observada en Ulva lactuca expuesta a una concentración baja de nitrato (Carr y Bjork 2003, Cabello-Pasini y Figueroa 2005). Evidentemente, la dispersión de los datos de la relación FB-TTE aumenta conforme disminuye el nitrógeno en el medio y el tejido. Es posible que los niveles bajos de clorofila en los tejidos incubados a niveles bajos de nitrato podrían causar la variabilidad de los datos. La absorptancia también disminuye y es más variable a niveles bajos de nitrato, lo que sugiere que la luz absorbida no fue utilizada eficientemente para la fotoquímica. Por ejemplo, la eficiencia fotoquímica disminuye como resultado de un menor número de centros funcionales del PSII en relación con antenas o debido a un aumento en la sección transversal de absorción del PSII, lo cual afecta la transferencia de energía entre los centros de reacción del PSII (Falkowski 1992).

La relación FB-TTE puede variar en respuesta a diferentes sumideros de nutrientes. Se ha mostrado que, además de la asimilación de carbono, otros sumideros, como la asimilación de nitrógeno, regulan estas relaciones (Figueroa et al. 2003). Por ejemplo, las pendientes de FB vs TTE o $\Phi_{\mathrm{PSII}}$ vs $\Phi_{\mathrm{O} 2}$ fueron menores en Ulva rotundata y Phorphyra leucosticta con una mayor capacidad de asimilación de nitrógeno, estimada como la actividad de la enzima nitrato reductasa y el contenido de nitrógeno interno, en relación 


\section{REFERENCES}

Atkinson MJ, Smith SV. 1983. CNP ratios of benthic marine plants. Limnol. Oceanogr. 28: 568-574.

Babin M, Morel A, Claustre H, Bricaud A, Kolber A, Falkowski PG. 1996. Nitrogen- and irradiance-dependent variations of the maximum quantum yield of carbon fixation in eutrophic, mesotrophic and oligotrophic marine systems. Deep-Sea Res. 43: $1241-1272$.

Beer S, Bjork M. 2000. Measuring rates of photosynthesis of two tropical seagrasses by pulse amplitude modulated (PAM) fluorometry. Aquat. Bot. 66: 69-76.

Beer S, Axelsson L. 2004. Limitations in the use of PAM fluorometry for measuring photosynthetic rates of macroalgae at high irradiances. Eur. J. Phycol. 39:1-7.

Cabello-Pasini A, Figueroa FL. 2005. Effect of nitrate concentration on the relationship between photosynthetic oxygen evolution and electron transport rate in Ulva rigida (Chlorophyta). J. Phycol. 41: 1169-1177.

Cabello-Pasini A, Lara-Turrent C, Zimmerman RC. 2002. Effect of storms on photosynthesis, carbohydrate content and survival of eelgrass populations in a coastal lagoon and the adjacent open ocean. Aquat. Bot. 74: 149-164.

Cabello-Pasini A, Muñiz-Salazar R, Ward DH. 2003. Annual variations of biomass and photosynthesis in Zostera marina $\mathrm{L}$. along the Pacific coast of Baja California, Mexico. Aquat. Bot. 76: 31-47.

Cabello-Pasini A, Muñiz-Salazar R, Ward DH. 2004. Biochemical characterization of the eelgrass Zostera marina at its southern distribution limit in the North Pacific $=$ Caracterización bioquímica del pasto marino Zostera marina en el límite sur de su distribución en el Pacífico Norte. Cienc. Mar. 30: 21-34.

Cancemi G, Buia M, Mazzella L. 2002. Structure and growth dynamics of Cymodocea nodosa meadows. Sci. Mar. 66: 365-373.

Carr H, Bjork M. 2003. A methodological comparison of photosynthetic oxygen evolution and estimated electron transport rate in tropical Ulva (Chlorophyceae) species under different light and inorganic carbon conditions. J. Phycol. 39: $1125-1131$.

Corzo A, Niell FX. 1991. Determination of nitrate reductase activity in Ulva rigida C. Agardh by the in situ method. J. Exp. Mar. Biol. Ecol. 146: 181-191.

Edwards GE, Baker NR. 1993. Can $\mathrm{CO}_{2}$ assimilation in maize leaves be predicted accurately from chlorophyll fluorescence analysis? Photosynthesis Res. 37: 89-102.

Elrifi IR, Turpin DH. 1986. Nitrate and ammonium induced photosynthetic suppression in N-limited Selenastrum minutum. Plant Physiol. 81: 273-279.

Falkowski PG. 1992. Molecular ecology of phytoplankton photosynthesis. In: Falkowski PG, Woodhead A (eds.), Primary Productivity and Biogeochemical Cycles in the Sea. Plenum Press, New York, pp. 47-67.

Falkowski PG, Raven JA. 1997. Aquatic Photosynthesis. Blackwell Publishers, New York, 384 pp.

Figueroa FL, Jimenez C, Viñegla B, Perez-Rodriguez E, Aguilera J, Flores-Moya A, Altamirano M, Lebert M, Hader DP. 2002. Effects of solar UV radiation on photosynthesis of the marine angiosperm Posidonia oceanica from southern Spain. Mar. Ecol. Prog. Ser. 230: 59-70.

Figueroa FL, Conde-Alvarez R, Gomez I. 2003. Relations between electron transport rates by pulse amplitude modulated chlorophyll fluorescence and oxygen evolution in macroalgae under different light conditions. Photosynthesis Res. 75: 259-275. con lo observado en Ulva olivascens (Figueroa et al. 2003). Como se mencionó anteriormente, la vía asimilatoria básica del nitrógeno inorgánico depende estrechamente del carbono orgánico $\mathrm{y}$, por lo tanto, la limitación de nitrógeno incrementa la asignación de carbono orgánico a los lípidos y carbohidratos (Falkowski y Raven 1997). Babin et al. (1996) encontraron que el rendimiento cuántico máximo varía en función de la concentración de nitrato en las muestras de fitoplancton. En contraste, en condiciones enriquecidas con nitrógeno (como en el presente estudio), una súbita asimilación de nitrógeno podría inhibir la actividad de la enzima RUBISCO y, consecuentemente, los electrones podrían ser usados para la asimilación de nitrato y el flujo respiratorio de carbono aumentaría para proporcionar esqueletos de carbono (Turpin 1991).

En general, las razones $\mathrm{C} / \mathrm{N}$ observadas en $C$. nodosa caen dentro del intervalo descrito para macrófitos marinos (Atkinson y Smith 1983). En estas plantas acuáticas, la mayor parte del carbono orgánico y nitrógeno se encuentra en los componentes estructurales, lo que sugiere que la respiración oscura se relaciona fuertemente con la formación de la biomasa. Así, es posible que la disminución de la razón $\mathrm{C} / \mathrm{N}$ conforme incrementó el nivel de nitrato en el medio podría ser resultado de una supresión transitoria de la fijación fotosintética del carbono debido a una competencia entre el ciclo de Calvin y la asimilación de nitrógeno. No es claro si otros procesos como el almacenamiento y la removilización de nitrógeno son activos en Cymodocea y requieren de mayor investigación.

Este estudio demuestra que la relación FB-TTE depende de la concentración de nitrógeno en el tejido de C. nodosa. La disponibilidad de nitrato también afecta varios parámetros, tales como el contenido de carbono, nitrógeno y clorofila en el tejido, así como la absorptancia del tejido. Por ende, es posible que la variación entre muestras dentro del mismo estudio y entre estudios puede ser resultado de las diferencias del nivel de nitrógeno en el tejido. Nuestro estudio también sugiere que la relación FB-TTE en las poblaciones naturales de fanerógamas marinas puede variar debido a fluctuaciones naturales de la carga de nutrientes (i.e., eventos de surgencia).

\section{Agradecimientos}

Este trabajo fue apoyado por el Ministerio de Educación, Cultura y Deporte (AGL 2005-02655) y la Junta de Andalucía (RNM-295), España. El primer autor recibió apoyo del Ministerio de Educación, Cultura y Deporte de España (SAB2002-0209).

Traducido al español por Christine Harris. 
Franklin LA, Badger MR. 2001. A comparison of photosynthetic electron transport rates in macroalgae measured by pulse amplitude modulated chlorophyll fluorometry and mass spectrometry. J. Phycol. 37: 756-767.

Genty B, Briantais J, Baker NR. 1989. The relationship between the quantum yield of photosynthetic electron transport and quenching of chlorophyll fluorescence. Biochim. Biophys. Acta 990: 87-92.

Gordillo FJL, Jimenez C, Chavarría J, Niell FX. 2001. Photosynthetic acclimation to photon irradiance and its relation to chlorophyll fluorescence and carbon assimilation in the halotolerant green alga Dunaliella viridis. Photosynthesis Res. 68: 225-235.

Grzymski J, Johnsen G, Sakshaug E. 1997. The significance of intracellular self-shading on the biooptical properties of brown, red, and green macroalgae. J. Phycol. 33: 408-414.

Herzig R, Falkowski PG. 1989. Nitrogen limitation in Isochrysis galbana. 1. Photosynthetic energy conversion and growth efficiencies. J. Phycol. 25: 462-471.

Inskeep WP, Bloom PR. 1985. Extintion coefficients of chlorophyll $a$ and $b$ in N,N-dimethylformamide and $80 \%$ acetone. Plant Physiol. 77: 483-485.

Kolber Z, Wyman K, Falkowski PG. 1990. Natural variability in photosynthetic energy conversion efficiency: A field study in the Gulf of Maine. Limnol. Oceanogr. 35: 72-79.

Ochoa-Izaguirre MJ, Soto-Jiménez MF. 2013. Evaluation of nitrogen sources in the Urías lagoon system, Gulf of California, based on stable isotopes in macroalgae $=$ Evaluación de las fuentes de nitrógeno en el sistema lagunar de Urías, golfo de California, mediante el uso de isótopos estables en macroalgas. Cienc. Mar. 39: 413-430.

http://dx.doi.org/10.7773/cm.v39i4.2285

Olesen B, Enriquez S, Duarte CM, Sand-Jensen K. 2002. Depthacclimation of photosynthesis, morphology and demography of Posidonia oceanica and Cymodocea nodosa in the Spanish Mediterranean Sea. Mar. Ecol. Prog. Ser. 236: 89-97.

Porra RJ, Thomson WA, Kriedemann PE. 1989. Determination of accurate extinction coefficients and simultaneous equations for assaying chlorophylls $a$ and $b$ extracted with four different solvents: Verification of the concentrations of chlorophyll standards by atomic absorption spectroscopy. Biochim. Biophys. Acta 975: 384-394.

Quiroz-Vázquez P, Ibarra Obando SE, Meling-López AE. 2005. Composition of the epifaunal community associated with the seagrass Zostera marina in San Quintin Bay, Baja California. Bull. South. Calif. Acad. Sci. 104: 100-112.

Ralph PJ, Burchett MD. 1998. Photosynthetic response of Halophila ovalis to heavy metal stress. Environ. Pollut. 103: 91-101.

Schrandt MN, Cebrián J, Darrow ES, Dalrymple DJ, Marco-Méndez C, Ferrero-Vicente LM, Heck KL, Sánchez-Lizaso JL. 2015. Evidence of short-term burial response by benthic macrofauna associated with the Mediterranean seagrass Cymodocea nodosa $=$ Evidencia de la respuesta a un enterramiento a corto plazo de la fauna macrobentónica asociada a la fanerógama marina del Mediterráneo Cymodocea nodosa. Cienc. Mar. 41: 371-385.

Schreiber U, Neubauer C. 1990. $\mathrm{O}_{2}$ dependent electron flow, membrane energization and mechanism of non-photochemical quenching of chlorophyll fluorescence. Photosynthesis Res. 25: 279-293.

Schreiber U, Bilger W, Neubauer C. 1994. Chlorophyll fluorescence as a nonintrusive indicator for rapid assessment of in vivo photosynthesis. In: Schulze E, Caldwell M (eds.), Ecophysiology of Photosynthesis. Springer, Berlin, pp. 49-70.

Sokal RR, Rohlf FJ. 1995. Biometry. WH Freeman and Company, New York, 887 pp.

Turpin DH. 1991. Effects of inorganic N availability on algal photosynthesis and carbon metabolism. J. Phycol. 27: 14-20.

Webb WL, Newton M, Starr D. 1974. Carbon dioxide exchange of Alnus rubra. A mathematical model. Oecologia 17: 281-291.

Young E, Beardall J. 2003. Rapid ammonium- and nitrate-induced perturbations to chl $a$ fluorescence in nitrogen-stressed Dunaliella tertiolecta (Chlorophyta). J. Phycol. 39: 332-342.

Zaitsev O, Trasviña-Castro A, Linero-Cueto J, Gaxiola-Castro G, Cepeda-Morales J. 2014. Oceanographic conditions over the continental shelf off Magdalena Bay (Mexico) in 2011-2012= Condiciones oceanográficas en la plataforma continental frente a bahía Magdalena (México) en 2011-2012. Cienc. Mar. 40: 89-112.

http://dx.doi.org/10.7773/cm.v40i2.2314

Received November 2014, accepted February 2015. 